\title{
Life history plasticity and reproductive strategy enabling the invasion of Ligia exotica (Crustacea: Isopoda) from the littoral zone to an inland creek
}

\author{
Min-Li Tsai ${ }^{1,2}$, Chang-Feng Dai ${ }^{1, *}$ \\ ${ }^{1}$ Institute of Oceanography, National Taiwan University, Taipei 106, Taiwan, ROC \\ ${ }^{2}$ National Museum of Marine Biology and Aquarium, 2 Houwan Road, CheCheng, Pintung 944, Taiwan, ROC
}

\begin{abstract}
A population of the marine isopod Ligia exotica was found in an inland habitat subject to unpredictable aridity. We studied the demography of littoral and inland populations in an attempt to define the variations in life history enabling this inland invasion of L. exotica. Although the 2 populations have similar steady recruitment and age structures, the patterns of size-specific contribution to yearly reproduction differ. The reproductive event itself may cause mortality in females. Both the net reproductive rate and the intrinsic rate of population growth show that both populations are increasing at similar rates. The longer generation time and the greater minimum age/size at reproduction of the inland population indicate that inland females may postpone the onset of reproduction. This delayed maturity may be an adaptive strategy allowing the inland colonization of L. exotica. Inland females are larger at time of reproduction, invest more in reproduction, and produce fewer but larger eggs/juveniles than do littoral females. These differences in the life history traits of $L$. exotica suggest life history plasticity in response to environmental changes. The production of fewer but larger eggs/juveniles of the inland population as a consequence of delayed maturity suggests that increasing offspring size is more important than higher fecundity in enabling $L$. exotica to colonize an inland habitat. The smaller individuals of L. exotica, with a lower resistance to desiccation due to high surface-area/volume ratios, have a higher mortality, especially during the juvenile stage. Because of the periodical and unpredictable aridity of the inland habitat, the mortality of inland juveniles is higher than that of littoral juveniles, and the strategy of producing larger offspring may favor inland colonization of L. exotica. For the successful invasion from littoral to inland areas, mortality may be the main selective factor determining life history traits: age and body size at maturation may be determined by age/size-specific survivorship, and the mortality of juveniles would seem to be sizedependent.
\end{abstract}

KEY WORDS: Life history plasticity $\cdot$ Ligia exotica $\cdot$ Offspring size $\cdot$ Reproductive strategy

Resale or republication not permitted without written consent of the publisher

\section{INTRODUCTION}

Demography, the key to life history theory, allows us to assess the strength of selection on life history traits. Life histories deal directly with natural selection, fitness, adaptation, and constraints. The evolution of life history traits and their plasticity determines the population dynamics of a species (Stearns 1992). The basic assumption of optimal theory is that, at each stage in its

\footnotetext{
*Corresponding author. E-mail: corallab@ccms.ntu.edu.tw
}

life history, an optimum fraction of an organism's available material should be diverted to maximizing total reproduction during its lifetime. The energy expenditure of maternal organisms on their offspring focuses on the number of offspring that each maternal organism can produce and the fitness of individual offspring (Smith \& Fretwell 1974, Reznick \& Yang 1993). Life history theory is concerned with how resources are allocated to different functions of an organism and the circumstances under which different strategies evolve. Organisms belonging to the same species but living in different habitats often display different combinations 
of life history traits, and comparative studies on such variations provide insight into evolutionary processes (Reznick \& Endler 1982, Eckelbarger \& Watling 1995, Ellers \& van Alphen 1997).

Ligia exotica, a semelparous isopod, has so far been regarded as a cosmopolitan marine species. It is widely distributed in the littoral zone and can be found on coasts around Taiwan. However, an inland population of $L$. exotica was found colonizing the banks of a hill creek on the Hengchun Peninsula in southern Taiwan (Tsai 1997). The inland habitat of $L$. exotica consists mainly of uplifted reef limestone. The creek bed and banks are composed of reef fragments and are covered by a layer of dense sediment. Most of the Hengchun Peninsula is surrounded by fringing reefs, with scattered sandy beaches carved out of them. A sandy deposit at the inlet area intercepts the creek. Coral reefs in the Hengchun Peninsula, lying on the accretion wedge of the Eurasian Plate, have been uplifted rapidly due to the ongoing arc-continent collision between the Eurasian and the Philippine tectonic plates (Wang \& Burnett 1990).

The colonization by Ligia exotica in the inland creek may have 2 possible scenarios. The isopods may represent a population which invaded from the littoral area, or a relict population associated with the rapid uplift of land which was isolated from the littoral area. In either case, the inland population of $L$. exotica represents an interesting example for studying the effect of habitat change on life history traits. Environmental conditions differ between the littoral zone and inland creek in many ways (Table 1 ). The inland habitat of $L$. exotica is subject to unpredictable aridity. The flow of this creek is rain-dependent, and it may occasionally dry out. The features of the watercourse may shift frequently due to flash-floods after precipitation. The microhabitat of inland $L$. exotica is characterized by greater variations in both air temperature and humidity than the littoral zone (Table 1). This inland colonization of $L$. exotica therefore provides an excellent opportunity for studying how life history traits vary in response to environmental changes. In this study, we compare the demography of natural populations of $L$. exotica in the 2 environments in an attempt to determine what combination of life history traits would favor such invasion from the littoral to an inland creek.

\section{MATERIALS AND METHODS}

Study site. The 2 sampling sites are located on the east coast of the Hungchun Peninsula, southern Taiwan (Fig. 1). The littoral population of Ligia exotica is distributed in the supralittoral zone of a rocky shore in an area of about $1500 \times 20 \mathrm{~m}$. The substratum is emergent limestone, which in some places is covered by boulders. The inland population of $L$. exotica is distributed along the banks of a hill creek covered by muddy sediment and coral fragments. The air temperature and relative humidity of both microhabitats were recorded continually for $5 \mathrm{~d}$ bimonthly with a $\mathrm{HOBO}^{\mathrm{TM}}$ temperature logger and StowAway ${ }^{\mathrm{TM}}$ humidity logger (Onsey Instrument Corporation, MA, USA).

Sampling. At each site, 9 to 27 quadrats (each $1 \times$ $1 \mathrm{~m}^{2}$ ) were sampled randomly along the coastline or the bank of the creek. The size of the quadrats was chosen based on a previous study which showed that quadrats larger than $1 \times 1 \mathrm{~m}$ did not significantly reduce the coefficients of variance among quadrats at both sites (Tsai 1997). Two adjacent quadrats were

Table 1. Comparisons of habitat features of littoral and inland populations of Ligia exotica in Hengchun Peninsula, southern Taiwan

\begin{tabular}{|c|c|c|}
\hline Feature & Littoral habitat & Inland habitat \\
\hline Habitat type: & Relatively constant & $\begin{array}{l}\text { Unstable; waterways may vary frequently } \\
\text { due to flash-floods after precipitation }\end{array}$ \\
\hline Microhabitat: & Surface of boulders, gaps & Crevices, tunnels \\
\hline Water resource: & Sea water; regular wave action & Freshwater; unstable; rain-dependent \\
\hline Vegetation: & Various seaweeds & Scattered shrubs \\
\hline Substratum: & Emergent reef bed covered by large boulders & Coral debris and dense fine sand \\
\hline $\begin{array}{l}\text { Air temperature of } \\
\text { microhabitat: }\end{array}$ & $\begin{array}{l}\text { Relatively constant } \\
\text { Min. } 22.4^{\circ} \mathrm{C} \\
\text { Max. } 38.7^{\circ} \mathrm{C} \\
\text { Average: } 25.5^{\circ} \mathrm{C}\end{array}$ & $\begin{array}{l}\text { Considerable variation } \\
\text { Min. } 17.3^{\circ} \mathrm{C} \\
\text { Max. } 44.5^{\circ} \mathrm{C} \\
\text { Average: } 24.7^{\circ} \mathrm{C}\end{array}$ \\
\hline $\begin{array}{l}\text { Humidity of } \\
\text { microhabitat: }\end{array}$ & $\begin{array}{l}\text { Relatively high and constant } \\
\text { Min. } 76 \% \\
\text { Max. } 100 \% \\
\text { Average: } 93 \%\end{array}$ & $\begin{array}{l}\text { Relatively low; greater variation than littoral } \\
\text { Min. } 55 \% \\
\text { Max. } 100 \% \\
\text { Average: } 76 \%\end{array}$ \\
\hline
\end{tabular}




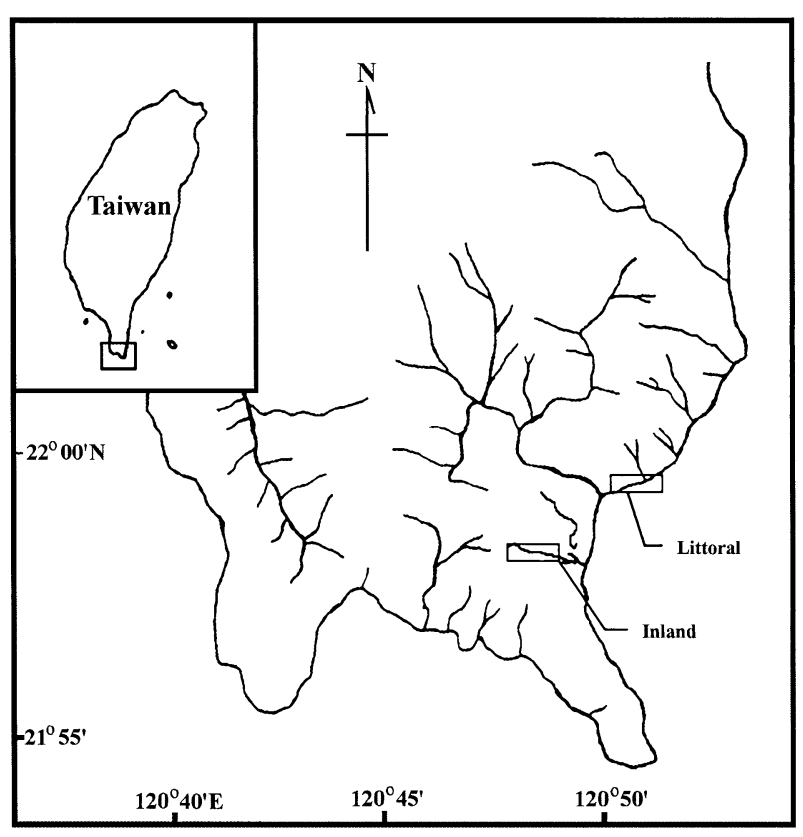

Fig. 1. Sampling sites of the littoral and inland populations of Ligia exotica in Hengchun Peninsula, southern Taiwan

separated by a distance of at least $20 \mathrm{~m}$ to minimize the effects of interference and migration. The sampling interval was approximately bimonthly from January 1994 to December 1995. Sampling was conducted in the evening, when Ligia exotica gathers on the underside of boulders. All individuals within a quadrat were collected. All boulders within a quadrat were gently removed and put into a plastic tank. The isopods were then swept from the boulder into the tank with an air jet. Individuals on rock surfaces and within crevices were pushed into a paper trap which was then emptied into the tank.

Estimation of life history traits. Estimations of life history traits mainly followed the method developed by Willows (1987) for Ligia oceanica. The life history traits examined included growth rate, breeding phenology, body size, sex ratio, mortality, minimum size at first reproduction, fecundity, egg size, and young size. Size-age relationship, size-fecundity relationship, size structure, size-specific mortality, and yearly natality were also estimated. Both mark-recapture and raising experiments were conducted to estimate the sizespecific growth rate. Large individuals (telson length $>10 \mathrm{~mm}$ ) were captured, marked with superglue and paint, and then released after measuring their body weight. Smaller individuals (telson length $<10 \mathrm{~mm}$ ) were raised in the laboratory. Within a week, the isopods were recaptured and weighed. The high intensity and short duration of the experiment minimized the problem of mark loss through molting. The isopods were then dried in an oven at $100^{\circ} \mathrm{C}$ for $48 \mathrm{~h}$. All data are presented as dry weight to enable comparison with later studies. A previous study had shown that percentage water content is constant and independent of body size in L. exotica (Tsai et al. 1998). The size-age relationship was estimated by the growth rate of each size class. The age of an individual was estimated based on the mean size of juveniles when first released from a brood pouch. The age of any one size class was calculated by size-specific growth rate. The size-age relationship was used for the transformation of body size data into age in subsequent analyses.

Minimum size at first reproduction was defined as the smallest gravid female recorded in the collections, and this minimum size was regarded as the size/age at maturity. Only gravid females with eggs showing no signs of development were measured to reduce the variances caused by different developmental stages and overestimation of the density of gravid females. Body mass, brood mass, fecundity, and egg mass were measured and calculated using some of these gravid females with undeveloped eggs. Reproductive allocation was calculated as the proportion of both brood weight (egg mass) and juvenile biomass to female weight.

The size-fecundity relationship was established by a simple linear regression model, and was used in further estimations of size-specific fecundity for a given size class. Gravid females with embryos in later stages were raised in the laboratory, and the number and size of young released were measured. The proportional loss $\left(v_{x}\right)$ arising from brood pouch mortality was assessed as the difference between the mean number of eggs and number of young released. The estimation of yearly reproduction $\left(N_{x}\right)$ followed the method of Willows (1987). The average density of females $\left(D_{x}\right)$, and the proportion of gravid females in each size class $\left(p_{x}\right)$ were assessed. Yearly reproduction is calculated as:

$$
N_{x}=D_{X} \times 2 m_{X} \times p_{X} \times\left(1-v_{X}\right)
$$

where $2 m_{x}$ is the weight-specific fecundity calculated from the size-fecundity regression under the assumption that the male:female ratio is 1.

Demographic analysis. Average survivorship curves and life tables were constructed based on the density estimates for each size class on each sampling occasion with different intervals. The size range which individuals of each size class should have attained at the subsequent sampling was calculated by the size-specific growth rate. Only those females within the expected size range at the subsequent sampling were considered to belong to the same size class, and were used for assessing survivorship. This approach is justified given the stable size distribution and limited variation in population density between years (Willows 1987). 
The net reproductive rate, $R_{0}$, the intrinsic rate of population growth, $r$, and the generation time, $T$, were calculated by the equations (Birch 1948):

$$
\begin{aligned}
& R_{0}=\sum_{x=0}^{\infty} 1_{x} \times m_{x} \\
& \sum_{x=0}^{\infty} e^{-r \cdot x} 1_{x} \times m_{X}=1 \\
& R_{0}=e^{r \cdot T}
\end{aligned}
$$

Reproductive value, $V_{\mathrm{x}}$, was calculated as:

$$
V_{X^{\prime}}=\frac{1}{1_{X}} \sum_{X=X^{\prime}}^{\infty} 1_{X} \times m_{X}
$$

(Fisher 1930, Stearns 1976).

\section{RESULTS}

\section{Recruitment and population structure}

In both the littoral and inland populations of Ligia exotica, daily growth rates varied between size classes. Growth rates of juveniles increased quickly after their release from the brood pouch, reached similar high levels in the size class ranging from 15 to $35 \mathrm{mg}$ dry wt, and then gradually decreased (Fig. 2). The turning point of the growth rate curve corresponded roughly to the age/size at first reproduction. This suggests that an energy trade-off exists between individual growth and reproduction.

In general, both populations showed a similar sizeage relationship. The results of a Kolmogorov-Smirnov test showed that the age-histograms of the 2 populations were similar among sampling months $(p>0.05)$ and between years $(p>0.05)$. In both populations, juveniles were released at a steady rate, and no obvious recruitment peak could be identified throughout the sampling period. Within each population, no significant difference in the quantity of recruitment could be found either among sampling months (littoral: $p>0.05$; inland: $\mathrm{p}>0.05$ ) or between years (littoral: $\mathrm{p}>0.05$; inland: $p>0.05$ ). However, the dry weight of newly released inland juveniles was significantly heavier $(\mathrm{p}<$ 0.001 ) than of those from the littoral. This indicates that inland females release larger offspring than littoral females.

\section{Sex ratio and size-fecundity relationship}

The results of $2 \times 9$ contingency table tests showed that female/male ratios among size classes differed in both populations (littoral: $\chi^{2}=759.19, \mathrm{p}<0.001$; inland: $\left.\chi^{2}=490.49, \mathrm{p}<0.001\right)$. For those individuals lighter than $35 \mathrm{mg}$ dry weight, the sex ratios of both populations were approximately 1:1 (Table 2). However, for individuals heavier than $35 \mathrm{mg}$ dry weight (i.e. approaching body size at reproduction), the number of males significantly exceeded that of females (Table 2). This suggests that reproduction may cause more mortality in females than in males. In both populations, the relationship between female size and fecundity fit a simple linear regression model well (Fig. 3). The slopes of the size-fecundity regression lines of both populations were similar $(p>0.05)$, but the intercepts differed $(\mathrm{p}<0.001)$. The size-fecundity relationships were then used to calculate the size-specific fecundity of each population.

\section{Yearly reproduction, survivorships and life tables}

Yearly reproduction was estimated for both populations (Table 3). The midpoint of each size class and mean weight of brood-carrying females were used to calculate the average female fecundity $\left(2 m_{x}\right)$ based on the sizefecundity regression models. Although the total reproduction of littoral and inland populations were similar, the distribution patterns of young released by each maternal size class differed. A contribution index of each

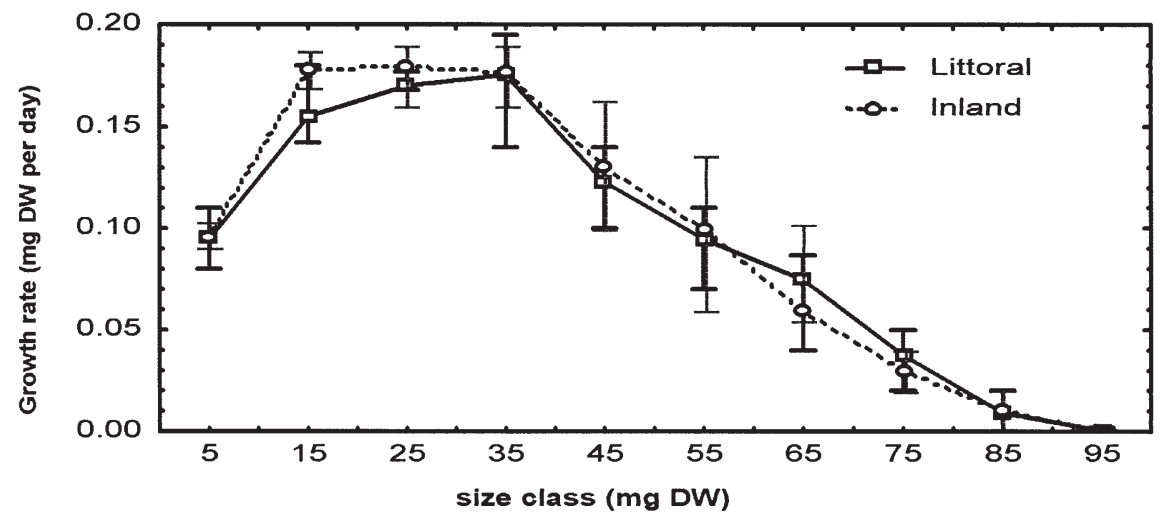

Fig. 2. Ligia exotica. Size-specific growth rates (dry wt, DW) of different size classes for littoral and inland populations 
Table 2. Ligia exotica. Percentage of females in each size class in the 2 populations, and results of $\chi^{2}$ test on sex ratio departure from 1:1. ns: not significant at $\mathrm{p}>0.05 ;{ }^{* *}$ significant at $\mathrm{p}<0.01{ }^{* * *}$ significant at $\mathrm{p}<0.001$

\begin{tabular}{|c|c|c|c|c|c|c|c|c|}
\hline \multirow{2}{*}{$\begin{array}{l}\text { Size class } \\
(\mathrm{mg})\end{array}$} & \multicolumn{4}{|c|}{ Littoral population } & \multicolumn{4}{|c|}{ Inland population } \\
\hline & $\begin{array}{c}\text { Total } \\
\text { individuals }\end{array}$ & $\begin{array}{c}\% \text { of } \\
\text { females }\end{array}$ & $\chi^{2}$ & $\mathrm{p}$ & $\begin{array}{c}\text { Total } \\
\text { individuals }\end{array}$ & $\begin{array}{c}\% \text { of } \\
\text { females }\end{array}$ & $\chi^{2}$ & $\mathrm{p}$ \\
\hline 5 & 688 & 49.74 & 0.01 & ns & 546 & 50.91 & 0.09 & ns \\
\hline 15 & 1006 & 51.45 & 0.45 & ns & 896 & 50.04 & 0.00 & ns \\
\hline 25 & 1645 & 50.74 & 0.19 & ns & 1044 & 50.48 & 0.05 & ns \\
\hline 35 & 1245 & 50.10 & 0.31 & ns & 1020 & 47.49 & 1.33 & ns \\
\hline 45 & 756 & 44.08 & 10.73 & $* *$ & 964 & 46.00 & 3.16 & ns \\
\hline 55 & 563 & 39.10 & 26.87 & $* * *$ & 856 & 40.50 & 15.47 & $* * *$ \\
\hline 65 & 458 & 29.28 & 78.82 & $* * *$ & 732 & 37.97 & 21.47 & $* * *$ \\
\hline 75 & 514 & 12.60 & 286.88 & $* * *$ & 440 & 24.45 & 60.97 & $* * *$ \\
\hline 85 & 392 & 0.25 & 388.01 & $* * *$ & 320 & 3.13 & 180.23 & $* * *$ \\
\hline Total & 7267 & 36.38 & 257.66 & $* * *$ & 6818 & 39.00 & 166.84 & $* * *$ \\
\hline
\end{tabular}

size class to total reproduction was calculated by dividing the reproduction of each size class by total natality. Total reproduction of the littoral population was contributed to mainly by size classes below $60 \mathrm{mg}$ dry weight, while the contribution of larger size classes (>60 mg) to total reproduction declined rapidly (Fig. 4a). The total reproduction of the inland population was contributed to mainly by larger size classes, with a maximum contribution by the 60 to $70 \mathrm{mg}$ size class (Fig. $4 \mathrm{~b}$ ).

The survival rate of inland juveniles in the first several months after release was lower than that of littoral juveniles (Table 4, Fig. 5). Before the onset of reproduction, males and females had similar life expectancies in both populations. However, the life expectancy of females was lower than that of males after the onset of reproduction (Fig. 5). The maximum longevity of littoral males was similar to that of inland males (about $25 \mathrm{mo}$ ), but the longevity of inland females (about $22 \mathrm{mo}$ ) was longer than that of littoral females (about $18 \mathrm{mo}$ ). This indicates that the reproductive event may affect the longevity of females.

\section{Fitness, life histories and reproductive traits}

The net reproductive rates were similar, and greater than $1\left(R_{0}=1.56\right.$ and 1.54 for littoral and inland populations, respectively). The intrinsic rates of population growth were slightly greater than $0(r=0.037$ and 0.035 per generation for littoral and inland populations, respectively). This indicates that both populations were increasing at similar rates. The estimated generation time of the inland population (13.87 mo) was longer than that of the littoral population (11.32 mo, Table 5). This suggests that the inland population may postpone the onset of reproduction, and consequently a larger female size would be attained at reproduction over that of the littoral population.

Comparisons of life history traits between littoral and inland populations showed that the inland population had a longer life span, a later maturity, a lower brood pouch mortality, and a longer generation time than the littoral population (Table 6). The 2 populations also showed significant differences in several reproductive traits (Table 7). Inland females had a larger body size at reproduction $(p<0.01)$, invested more materials in reproduction $(\mathrm{p}<0.001)$, and produced heavier broods $(p<0.001)$ with fewer $(p<0.001)$ but larger offspring $(\mathrm{p}<0.001)$ than littoral females.

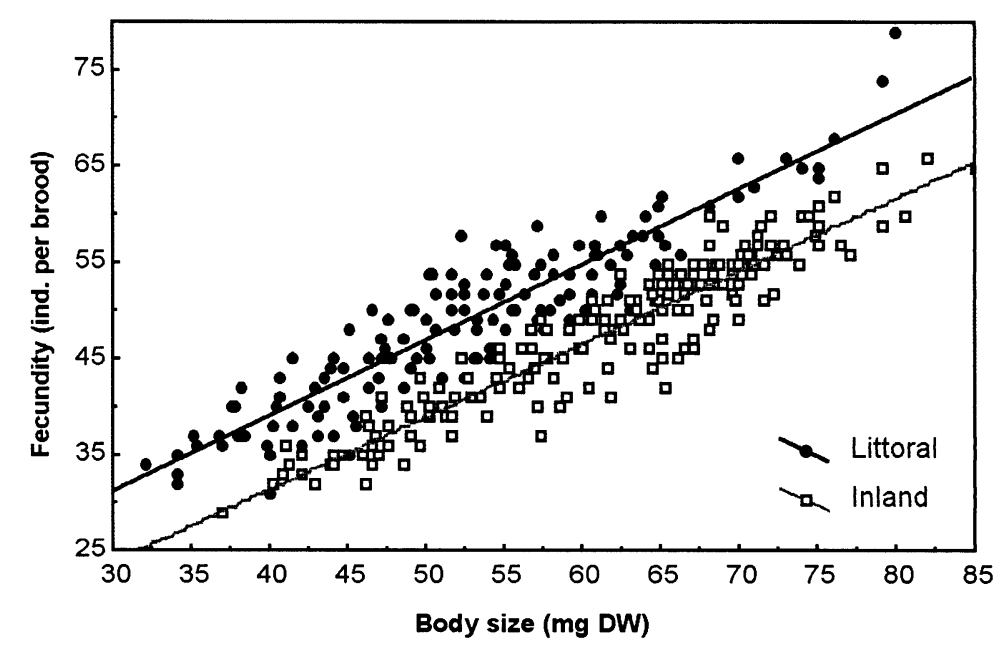

Fig. 3. Ligia exotica. Size-fecundity regression of littoral $(y=8.80+$ $\left.0.782 x, F_{1,98}=795.7, \mathrm{p}<0.001\right)$ and inland $\left(y=0.243+0.788 x, F_{1,80}=\right.$ 1116.2, $\mathrm{p}<0.001)$ populations 
Table 3. Ligia exotica. Calculations of yearly reproduction for littoral and inland populations in 1994 and 1995. Size-classes (mg) are shown, followed by range in parentheses. $D x$ : female density; $2 m_{x}$ : weight-specific fecundity per individual (calculated from size-fecundity regression); $P_{X}$ : percentage of females with brood; $C r$ : egg standing crop; $V x$ : brood-pouch mortality; $N_{X}$ : reproduction; $Y N x$ : yearly reproduction

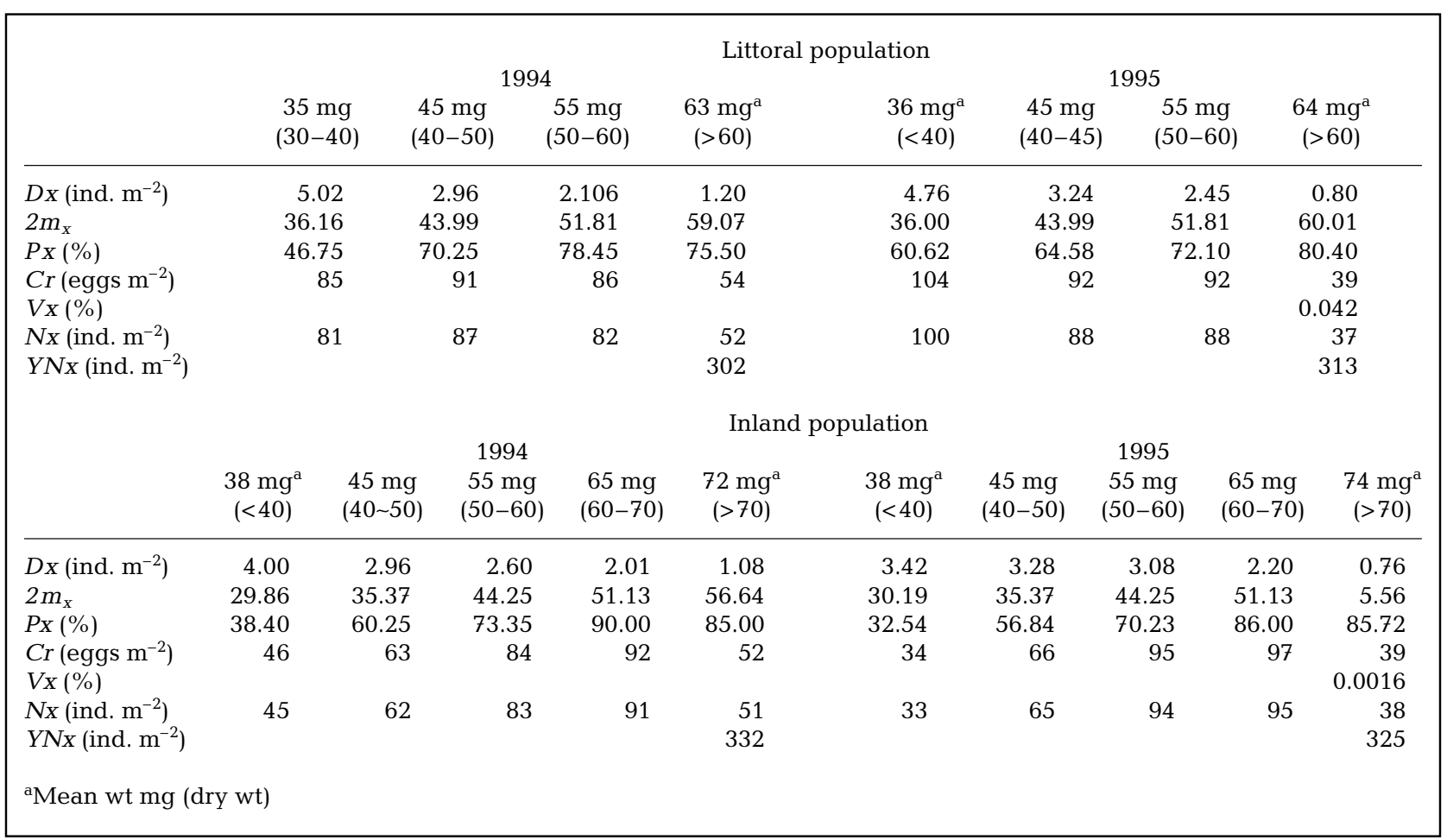

Table 4. Ligia exotica. Life tables for females of littoral and inland populations. $x$ : size class (mg dry wt); $x^{\prime}$ : age class (mo): Sx: survivors; $D x$ : dying; $d x$ : mortality rate per hundred at beginning of age interval $x_{i} p x$ : survival rate per hundred at beginning of age interval $x_{i} l x$ : survival to age $x$

\begin{tabular}{|c|c|c|c|c|c|c|c|c|c|c|c|c|}
\hline \multirow[b]{2}{*}{$x$} & \multicolumn{6}{|c|}{ Littoral population } & \multicolumn{6}{|c|}{ Inland population } \\
\hline & $x^{\prime}$ & $S x$ & $D x$ & $d x$ & $p_{X}$ & $l x$ & $X^{\prime}$ & $S x$ & $D x$ & $d x$ & $p x$ & $l x$ \\
\hline 0 & 0 & 1000 & 902 & 0.90 & 0.10 & 1 & 0 & 1000 & 938 & 0.93 & 0.07 & 1 \\
\hline 5 & 3.4 & 98 & 12 & 0.12 & 0.88 & 0.098 & 2.9 & 62 & 12 & 0.19 & 0.84 & 0.062 \\
\hline 15 & 5.4 & 76 & 18 & 0.24 & 0.76 & 0.076 & 4.5 & 48 & 14 & 0.29 & 0.80 & 0.048 \\
\hline 25 & 6.9 & 58 & 22 & 0.38 & 0.62 & 0.058 & 6.3 & 37 & 11 & 0.30 & 0.44 & 0.037 \\
\hline 35 & 9.1 & 36 & 14 & 0.39 & 0.61 & 0.036 & 10.2 & 24 & 6 & 0.25 & 0.75 & 0.024 \\
\hline 45 & 11.4 & 20 & 9 & 0.45 & 0.55 & 0.020 & 11.6 & 18 & 2 & 0.11 & 0.89 & 0.018 \\
\hline 55 & 13.7 & 11 & 5 & 0.45 & 0.45 & 0.011 & 14.1 & 16 & 2 & 0.13 & 0.87 & 0.016 \\
\hline 65 & 15.5 & 6 & 6 & 1 & 0 & 0.006 & 16.7 & 12 & 4 & 0.33 & 0.67 & 0.012 \\
\hline 75 & & & & & & & 19.5 & 7 & 7 & 1 & 0 & 0.007 \\
\hline
\end{tabular}

\section{DISCUSSION}

\section{Life history variations}

Neither the littoral nor inland populations of Ligia exotica were at equilibrium densities $\left(R_{0}>1\right.$ and $\left.r>0\right)$. However, this did not affect the stability of the population structure, since the proportion of organisms in each age class was relatively stable. Each population might achieve a steady recruitment of young through different combinations of life history traits such as proportions of gravid females, fecundity, age of breeding, and size/age-specific mortality. Although the L. exotica populations in the 2 habitats had similar net reproductive rates and intrinsic rates of increase, the inland population had a longer generation time. In this case, the net reproductive rate $\left(R_{0}\right)$ proved an incomplete measure of fitness because it did not consider the 
(a) Littoral population

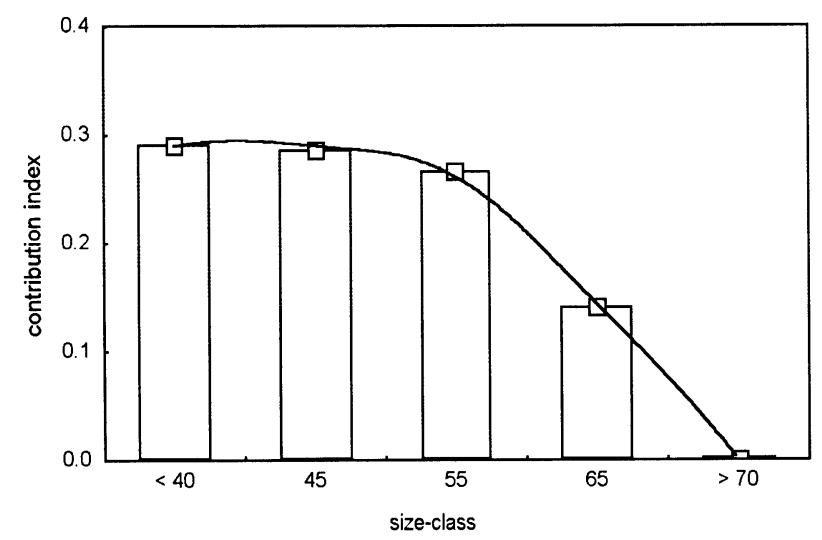

(b) Inland population

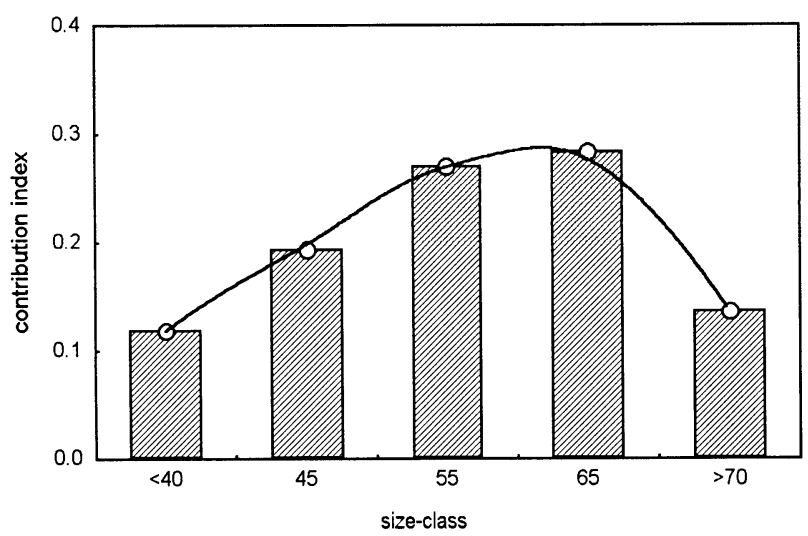

Fig. 4. Ligia exotica. Contribution of each size class to total reproduction of littoral and inland populations

effects of different generation times (Lande 1982, Stearns 1992). Both the longer generation time and the larger minimum size/age at reproduction of inland females indicate that the life cycle of inland females had been delayed. Littoral offspring had a higher brood pouch mortality (i.e. mortality occurring in the brood pouch during the development period from egg to juvenile). However, after being released, the littoral juveniles had a higher survival rate than did inland juveniles. In the brood pouch, the survivorship of offspring is mainly related to the internal environment afforded by the gravid female. Once the juveniles are released from the brood pouch, the external environment becomes the main factor affecting their survivorship. Inland females with larger body sizes may provide better internal conditions (perhaps available space/resources) for the egg/juvenile development in the brood pouch. However, the desiccation stress of the inland habitat may lead to higher mortality of juveniles after release.
The differences in the life history traits of littoral and inland populations may indicate life history plasticity of Ligia exotica in response to habitat change. The capability to modify their life history traits in different environments is possibly an adaptive strategy that is common among isopods or other crustaceans (Davis 1984). Geographic differences in life history traits have been reported in size at maturity and number of eggs in isopods (Sastry 1983). In California, the isopod Armadillidium vulgare breeds after $1 \mathrm{yr}$ at a small body size (Paris \& Pitelka 1962, Lawlor 1976a,b), but in other regions, it does not initiate breeding until after 2 yr, at a larger body size (Heeley 1941).

\section{Delayed maturity and its consequences}

Age at maturity is a key factor determining the sensitivity of each life history trait in response to selection pressure (Meats 1971, Green \& Painter 1975, Snell 1978). Both earlier and later maturity may lead to increased fitness. In some cases, earlier maturity is the

(a) Littoral population

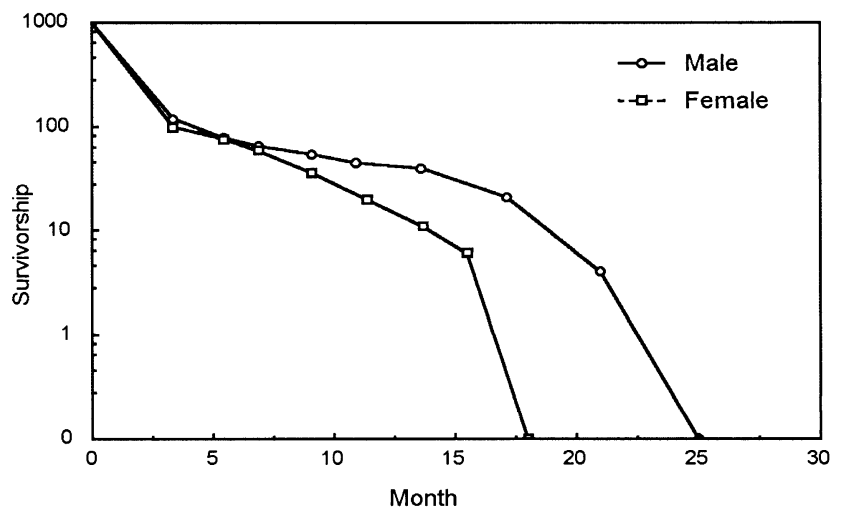

(b) Inland population

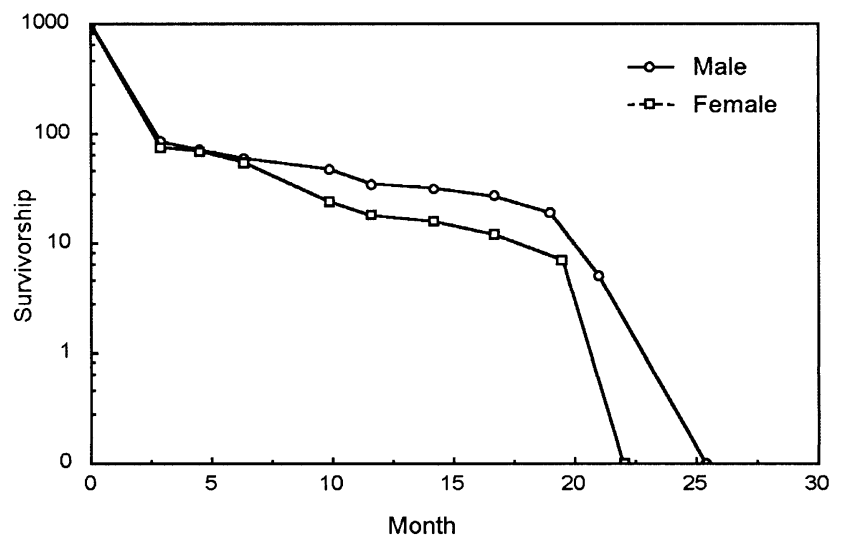

Fig. 5. Ligia exotica. Survivorship curves of male and female of littoral and inland populations 
Table 5. Ligia exotica. Estimations of net reproductive rate $\left(R_{0}\right)$, intrinsic rate of population growth $(r)$, generation time $(T)$, reproductive value $\left(V_{x}\right)$, and relative reproductive value $\left(V^{\prime}{ }_{x}\right)$, for littoral and inland populations. Age was calculated from the age-size regression

\begin{tabular}{|c|c|c|c|c|c|c|c|}
\hline Age (mo) & $l_{x}$ & $m_{x}$ & $l_{x} m_{x}$ & $x l_{x} m_{x}$ & $t l_{x} m_{x}$ & $V_{x}$ & $V^{\prime}{ }_{x}$ \\
\hline \multicolumn{8}{|c|}{ Littoral population } \\
\hline 9.10 & 0.036 & 18.08 & 0.65 & 22.78 & 5.92 & 43.19 & 27.77 \\
\hline 11.39 & 0.020 & 21.99 & 0.44 & 19.79 & 5.01 & 45.20 & 29.07 \\
\hline 13.68 & 0.011 & 25.91 & 0.29 & 15.67 & 3.90 & 42.18 & 27.13 \\
\hline 15.51 & 0.006 & 29.82 & 0.18 & 11.27 & 2.78 & 29.83 & 19.18 \\
\hline $\begin{array}{l}R_{0}=1.55 \\
r=0.037 \\
T=11.32\end{array}$ & & & & & & & \\
\hline \multicolumn{8}{|c|}{ Inland population } \\
\hline 10.24 & 0.024 & 14.93 & 0.36 & 15.40 & 3.97 & 59.12 & 38.46 \\
\hline 11.59 & 0.018 & 17.69 & 0.32 & 12.74 & 3.28 & 65.50 & 42.62 \\
\hline 14.14 & 0.016 & 21.63 & 0.35 & 21.40 & 5.50 & 53.19 & 34.61 \\
\hline 16.69 & 0.012 & 25.56 & 0.31 & 19.96 & 5.12 & 42.08 & 27.38 \\
\hline 19.50 & 0.007 & 28.32 & 0.20 & 12.92 & 3.32 & 28.29 & 18.40 \\
\hline \multicolumn{8}{|c|}{$R_{0}=1.537$} \\
\hline \multicolumn{8}{|c|}{$r=0.035$} \\
\hline \multicolumn{8}{|c|}{$T=13.87 \mathrm{mo}$} \\
\hline
\end{tabular}

Table 6. Ligia exotica. Life history traits of littoral and inland populations in Hengchun Peninsula, southern Taiwan. Data collected in 1994 and 1995. Weight-specific fecundity was based on $45 \mathrm{mg}$ female dry wt

\begin{tabular}{|lrr|}
\hline Life history trait & Littoral population & Inland population \\
\hline Maximum life span: & & \\
male & $25 \mathrm{mo}$ & $25 \mathrm{mo}$ \\
female & $18 \mathrm{mo}$ & $22 \mathrm{mo}$ \\
Minimum time to breed & $9.0 \mathrm{mo}$ & $10.1 \mathrm{mo}$ \\
Minimum size at reproduction & $34.74 \mathrm{mg}$ & $38.45 \mathrm{mg}$ \\
Mean time to breed & $13.3 \mathrm{mo}$ & $15.0 \mathrm{mo}$ \\
Breeding season & All year & All year \\
No. of breedings in lifetime & 1 & 1 \\
Weight-specific fecundity & 43.99 & 35.70 \\
Brood-pouch mortality & 0.042 & 0.016 \\
Net reproduction rate $\left(R_{0}\right)$ & 1.555 & 1.537 \\
Intrinsic population growth rate $(r)$ & 0.037 & 0.035 \\
Generation time $(T)$ & $11.32 \mathrm{mo}$ & $13.87 \mathrm{mo}$ \\
\hline
\end{tabular}

vantageous. Stearns (1992) suggested 2 important factors that may cause delay in maturity. First, if delaying maturity permits further growth and increasing fecundity with increasing maternal size, then delay in maturity would lead to higher fecundity. Second, if delaying maturity means that the quality of the offspring produced is higher, then delayed maturity would reduce the juvenile mortality of the offspring. In the case of the present study, the delayed maturity of inland $L$. exotica is possibly due to the second reason. Additionally, the longer generation time of the inland population does not seem to result in a significant increase in mortality (Fig. 5). Thus, due to the unpre-

simplest and most effective way of increasing fitness by increasing the chance of survival to maturity (Caswell \& Hastings 1980, Roff 1992, Stearns 1992). Individuals that mature earlier may have higher fitness because their offspring are born earlier and reproduce sooner (Hamilton 1966, Bell 1980). When the timing of maturity is earlier than the occurrence of the highest mortality in the life cycle, the benefit of earlier maturity would be theoretically maximal. Thus, the benefit of earlier maturity may depend on age/size-specific mortality. However, the high mortality of the early juvenile stages of Ligia exotica seems unlikely to favor evolution toward earlier maturity, and the very low fecundity associated with small maternal size is also disad- dictable aridity of the inland habitat and the high juvenile mortality of L. exotica, a strategy of delayed maturity may be advantageous for their successful invasion from the littoral to the inland creek. Tuljapurkar (1990) also suggested that delayed maturity can be advantageous: life cycle delays can increase individual fitness in strongly variable environments.

\section{Selection pressures on offspring size}

Body size may affect survival probabilities, reproductive output, and individual fitness in many organisms (Twombly \& Tisch 2000). Age-specific mortality 
Table 7. Ligia exotica. Comparison of reproductive traits of littoral and inland populations in Hengchun Peninsula, southern Taiwan. ${ }^{* * *}$ significant at level of $\mathrm{p}<0.001 ;{ }^{* *}$ significant at $\mathrm{p}<0.01$

\begin{tabular}{|lccc|}
\hline Reproductive traits & $\begin{array}{c}\text { Littoral } \\
\text { population }\end{array}$ & $\begin{array}{c}\text { Inland } \\
\text { population }\end{array}$ & $\mathrm{p}$ \\
\hline Mean no. of eggs per brood & 50.4 & 47.4 & ${ }^{* * *}$ \\
Mean no. of young per brood & 48.3 & 46.6 & ${ }^{* * *}$ \\
Brood-pouch mortality & 0.042 & 0.016 & ${ }^{* * *}$ \\
Mean brood weight & $10.4 \mathrm{mg}$ & $11.8 \mathrm{mg}$ & ${ }^{* * *}$ \\
Mean maternal somatic weight & $53.18 \mathrm{mg}$ & $57.74 \mathrm{mg}$ & ${ }^{* *}$ \\
Mean egg weight & $0.207 \mathrm{mg}$ & $0.243 \mathrm{mg}$ & ${ }^{* * *}$ \\
Mean juvenile weight & $0.32 \mathrm{mg}$ & $0.35 \mathrm{mg}$ & ${ }^{\mathrm{a}}$ \\
Reproductive investment & & & ${ }^{\mathrm{b}}$ \\
based on egg weight & $19.52 \%$ & $20.58 \%$ & ${ }^{* * *}$ \\
based on juvenile weight ${ }^{\mathrm{a}}$ & $30.33 \%$ & $33.32 \%$ & \\
after release & & & \\
b(Brood wt/maternal wt) $\times 100$ & & & \\
\hline
\end{tabular}

the fecundity, and that the inland habitat, with its periodical and unpredictable periods of desiccation, may favor females that produce larger juveniles. In many cases, offspring size is closely related to fitness (e.g., Parker \& Begon 1986, Lloyd 1987, Bauer 1994). Under the constraint of reproductive investment, inland females may allocate more material/energy to increasing offspring size rather than number. The variations in the life history traits between the 2 populations of $L$. exotica indicate life history plasticity in response to environmental change; this plasticity may allow them to exploit various habitats. may be an important factor in deciding life history traits (e.g., Schaffer 1974, Reznick \& Endler 1982, Roff 1992). In the life cycle of Ligia exotica, highest mortality occurs during the first few months after release, and juvenile mortality of the inland population was higher than that of the littoral population in the present study. However, in given arid conditions $\left(27^{\circ} \mathrm{C}, 85 \%\right.$ relative humidity) in the laboratory, inland juveniles in the fourth month after release displayed lower mortality (Tsai 1997). Tsai et al. (1998) demonstrated that the capability of $L$. exotica to resist desiccation was closely related to body size: large individuals with lower surface-area/volume ratios had higher desiccation resistance than smaller ones. The high juvenile mortality of L. exotica may be due to the small body size of its newly released juveniles. This may also explain why attaining a larger body size, especially in the juvenile stage, is important for inland $L$. exotica in reducing mortality due to desiccation stress. For the successful invasion from littoral to inland areas, mortality may be the main selective force driving life history traits. It is interesting to note that age and body size at maturation seem to be determined by age/size-specific survivorship, while mortality of juveniles seems to be sizedependent.

The larger maternal size of the inland population, as a consequence of delayed maturity, may be advantageous in producing more offspring to compensate for juvenile mortality or in producing larger juveniles. In the present study, inland females produced fewer but larger eggs instead of increasing their fecundity, due to the trade-off in egg size and number (Tsai \& Chen 1997). This indicates that in the inland population of Ligia exotica, offspring size is possibly subject to stronger selective pressure than
Acknowledgements. This study was supported by grants from the National Science Council, ROC (NSC 89-2811-B002-0042 to M.-L.T. and NSC 89-2811-B002-001 to C.-F.D.). We are grateful to Richard Sleboda for his editorial assistance.

\section{LITERATURE CITED}

Bauer G (1994) The adaptive value of offspring size among freshwater mussels (Bivalvia: Unionoidea). J Anim Ecol 63:933-944

Bell G (1980) The costs of reproduction and their consequences. Am Nat 116:45-76

Birch LC (1948) The intrinsic rate of natural increase of an insect population. J Anim Ecol 17:15-26

Caswell H, Hastings A (1980) Fecundity, developmental time, and population growth rate: an analytical solution. Theor Popul Biol 17:71-79

Davis RC (1984) Effects of weather and habitat structure on the population dynamics of isopods in a dune grassland. Oikos 42:387-395

Eckelbarger K, Watling JL (1995) Role of phylogenetic constraints in determining reproductive patterns in deep-sea invertebrates. Invertebr Biol 114:256-269

Ellers J, van Alphen JJM (1997) Life history evolution in Asobara tabida: plasticity in allocation of fat reserves to survival and reproduction. J Evol Biol 10:771-785

Fisher RA (1930) The genetical theory of natural selection. Clarendon, Oxford

Green RF, Painter PR (1975) Selection for fertility and development time. Am Nat 109:1-10

Hamilton WD (1966) The moulding of senescence by natural selection. J Theor Biol 12:12-45

Heeley W (1941) Observations on the life histories of some terrestrial isopods. Proc Zool Soc Lond B 111:79-149

Lande R (1982) A quantitative genetic theory of life history evoluton. Ecology 63:607-615

Lawlor LR (1976a) Parental and offspring fitness in terrestrial isopod Armadillidium vulgare (Latr.) (Crustacea: Oniscoidea). Evolution 30:775-785

Lawlor LR (1976b) Molting, growth and reproductive strategies in the terrestrial isopod Armadillidium vulgare (Latr.) (Crustacea: Oniscoidea). Ecology 57:1179-1194 
Lloyd DG (1987) Selection of offspring size and other size versus number strategies. Am Nat 129:800-817

Meats A (1971) The relative importance to population increase of fluctuations in mortality, fecundity, and the time variables of the reproductive schedule. Oecologia 6:223-237

Paris OA, Pitelka FH (1962) Population characteristics of the terrestrial isopod Armidillidium vulgare in California grassland. Ecology 43:229-248

Parker GA, Begon M (1986) Optimal egg size and clutch size: effects of environmental and maternal phenotype. Am Nat 128:575-592

Reznick D, Endler JA (1982) The impact of predation on life history evolution in Trinidadian guppies (Poecilia reticulata). Evolution 36:160-177

Reznick D, Yang AP (1993) The influence of fluctuating resources on life history: patterns of allocation and plasticity in female guppies. Ecology 74:2011-2019

Roff DA (1992) The evolution of life histories. Chapman \& Hall, London

Sastry AN (1983) Ecological aspects of reproduction. In: Bliss DE (ed) The biology of Crustacea, Vol 8. Academic Press, London, p 179-270

Schaffer WM (1974) Selection of optimal life histories: the effects of age structure. Ecology 55:291-303

Smith CC, Fretwell SD (1974) The optimal balance between size and numbers of offspring. Am Nat 108:499-506

Snell TW (1978) Fecundity, developmental time, and population growth rate. Oecologia 32:119-225

Editorial responsibility: Otto Kinne (Editor),

Oldendorf/Luhe, Germany
Stearns SC (1976) Life history tactics: a review of the ideas. Q Rev Biol 51:3-47

Stearns SC (1992) The evolution of life history. Oxford University Press, Oxford

Tsai ML (1997) Comparative study of life history and terrestrial invasion of isopods, Ligia exotica and L. taiwanensis in Hengchun Peninsula. PhD thesis, National Taiwan University, Taipei

Tsai ML, Chen HC (1997) Variation of reproductive traits of two semi-terrestrial isopods, Ligia exotica and L. taiwanensis (Crustacea: Ligiidae), in southern Taiwan. Zool Stud 36:33-41

Tsai ML, Dai CF, Chen HC (1998) Desiccation resistance of two semiterrestrial isopods, Ligia exotica and Ligia taiwanensis (Crustacea) in Taiwan. Comp Biochem Physiol 119A:361-367

Tuljapurkar S (1990) Delay reproduction and fitness in variable environments. Proc Natl Acad Sci USA 87: 1139-1143

Twombly S, Tisch N (2000) Body size regulation in copepod crustaceans. Oecologia 122:318-326

Wang CH, Burnett WC (1990) Holocene mean uplift rates across an active plate-collision boundary in Taiwan. Science 248:204-206

Willows RI (1987) Population dynamics and life history of two contrasting populations of Ligia oceanica (Crustacea: Oniscidea) in the rocky supralittoral. J Anim Ecol 56: 315-330

Submitted: May 2, 2000; Accepted: August 22, 2000

Proofs received from author(s): December 22, 2000 